\title{
Different Techniques being followed by the respondents for stress management by the KVK functionaries in Odisha
}

\author{
Aditya Kumar Malla ${ }^{\square}$ and Jeebanjyoti Behera \\ Ph.D. Research Scholar, Department of Extension Education, OUAT, Bhubaneswar, Odisha, India \\ Email: adityamalla32@gmail.com
}

\section{ABSTRACT}

Stress in general and occupational stress in particular has become the topics of discussion for the past several decades all over the world. As the agricultural sector by its very nature is a risk business, the attention given to agricultural workers in the national level in general and state level in particular as far stress and its management aspects are considered is minimal. This study research Different Techniques being followed by the Respondents for Stress Management by the KVK Functionaries in Odisha therefore, explored the situation of the Krishi Vigyan Kendras (KVK) functionaries as far as stress and its management aspects are considered. Stress levels of functionaries, sources of stress, consequences of stress, and coping mechanism to stress were studied. Random sampling was employed to select the sample of $16 \mathrm{KVKs}$ from the overall $33 \mathrm{KVKs}$ under 'Orissa University of Agriculture and Technology. Taking the small human resource capacity of the KVKs during the study time in to consideration, total enumeration (census method) was used for data collection. Finally, a total of 80 respondents were picked as sample respondents. Both qualitative and quantitative data were collected from the sample respondents using mailed questionnaire. Regarding the stress management techniques being followed by the sample respondents, it was indicated that time management techniques, physical exercise (prayer and listen to music) and social support were the stress copying mechanism the functionaries were using to minimize their stress. Generally the result of this study indicates that stress management aspect is complex issues which should be handled by both the individuals and the organizations properly in reference to the suggested model by the scholar.

Abbreviations: GOI-Government of India, ICAR-Indian Council of Agricultural research, K.V.K-Krishi Vigyan Kendra, O.U.A.T-Orissa University of Agriculture and Technology.

\section{INTRODUCTION}

Stress in general and occupational stress in particular along with its management aspect has attracted considerable attention all over the world including India. Currently, agricultural sector accounts for almost 60 and 65 percent of aggregate work force in India and the state of Odisha respectively (Odisha department of agriculture, 2013, Shukla and Garg, 2013). This clearly indicates large number of workers is deployed in this sector. As a means of bridging the gap between farming community and the research wing in agriculture as well as providing vocational education in agriculture and allied fields to the farming community, the government of India (GOI) through the Indian Council of Agricultural research (ICAR) decided to establish agricultural science centers by the name Krishi Vigyan Kendras in 1960's (Bano, 2011). Currently there are about 642 K.V.Ks in the whole nation including 33 in Odisha state

nation including 33 in Odisha state

Original Article

PII: S232247701900002-9

Rec. 19 December 2018

Acc. 20 April 2019

Pub. 25 June 2019

\section{Keywords}

Stress management, Time management, Individual stress coping technique,

Physical exercise,

Social support and Organizational techniques.

\section{(http://www.icar.org.in/files/KVK-Telephone- Directory.pdf).}

Stress in general and occupational stress in particular along with its management aspect has attracted considerable attention all over the world including India (Manshor et al., 2003). This is due to the fact that stress has detrimental effect on the individual's health and productivity of organizations. However, evidence indicates that most of the studies conducted in the country so far largely focused on occupational stress of employees of Banks, IT industry, Police, Teachers and the like (Shukla and Garg, 2013, Bhattacharya and Basu, 2007, Berg et al., 2006). The attention provided to the employees of agricultural sector to date is minimal.

As in most of the times agricultural work is carried out in the rural areas, it is subject to health hazards of the rural environment, as well as those inherent to the specific work processes involved (Olowogbon et al., 2019, Sparks et al., 2001). Psychosocial hazards are aspects of work that are associated 
with negative health and safety outcomes. The likes of job role, job characteristics and attributes, physical work conditions and technology, performance feedback and reward system, interpersonal relations at work, organizational structure and climate, along with personal problems can cause stress to the agricultural workers.

The Krishi Vigyan Kendra as a noble concept developed by Indian Council of Agricultural Research (ICAR) has a prime mandate of transferring agricultural technology from laboratories to farmer's field. These Krishi Vigyan Kendra's are district level extension organizations. In Odisha state there are 33 K.V.Ks (31 under O.U.A.T and 2 under ICAR) with around 375 employees.

\section{H METHODOLOGY}

A comprehensive list of all the K.V.Ks operating under O.U.A.T. were collected from the Directorate of Extension Education and a total of sixteen K.V.Ks were selected randomly for studying stress management practices of their functionaries. Based on the preliminary survey and the list obtained from the Directorate of Extension Education, it was identified that the maximum staff strength of a K.V.K is 16. Taking the small human resource capacity of the KVKs during the study time in to consideration, total enumeration (census method) was used for data collection. Finally, the first 80 respondents were considered to be the constituents of the research sample. Both qualitative and quantitative data were collected from the sample respondents using mailed questionnaire. Descriptive statistics such as mean, standard deviation were used to summarize and analyze the data on different techniques being followed by the respondents for stress management.

\section{RESULTS AND DISCUSSION}

\section{Different techniques being followed by the respondents for stress management}

Stress is a fact of life and individuals react to it in different ways. Some individuals deal with stressors in a positive way with a proper understanding of the phenomenon and its effect while other individuals or organizations do not. Taking appropriate action to reduce or prevent stress is beneficial for both the individual and organization.
Here, as the title of this thesis is 'Study on stress management practices of Krishi Vigya Kendras functionaries in Odisha' full attention was given to find out what management practices being followed by the respondents. The study viewed stress management from both the individuals/functionary's standpoint and the organization standpoint and findings are presented in the following tables/figures.

\section{A) Individual stress coping technique}

Simple identification of stress, its symptoms and consequences is not sufficient unless these are managed properly at least by the very individual who suffered. Therefore attempt was made by the scholar to probe inside the individual stress coping techniques.

\section{B) Time management}

Time management is an important element for people who maintain a busy schedule. They need to prioritize their activities to avoid stress from time pressure and overtime work. Time management helps to balance work and leisure time activities (Kathirvel, 2009). Time management technique in the KVK functionaries as means of reducing pressure or stress has been studied as the result is presented in the Figure 1.

The first and for most point of intervention in the context of stress management is the time variable which is the root cause of creating stress to individual who poorly mange time. However, in the study area the various approaches to time management like prioritizing activity by importance and urgency, knowing daily job cycle, scheduling activities according to priorities and finally making list of activities are some of the studied time management techniques which are acknowledge always by $77 . \%, 77.5 \%, 65 \%$ and $52.5 \%$ of respondents selected for the study. By virtue of experience as well as following the principle learning by doing this approach of time management was found to be relevant in the process of tenureship of working by functionaries in the KVK set up of the state.

\section{C) Physical exercise}

Physical exercises are other acceptable techniques for stress management which are followed by the KVK functionaries and reflected in the table 1. It is observed in this table that very feasible and practicable exercises are being regularly 
and occasionally performed by the functionaries in an attempt to reduce stress. The most practiced exercise in all those categories is prayer which is followed by $45 \%$ of the respondents. Listening to music is the most preferred technique which is sometimes followed by $68.75 \%$ of the respondents. These two techniques of exercise were found to be very easy, convenient and simple to understand and follow.

\section{D) Social support}

Man being a social animal, love to be in society and trying to become more sociable and consequently acceptable in the society. Many a time for social stability the individual members strive to be always stable, balanced and alert in the context of different events and happenings in their immediate environment which they want to cope. At times irrespective of the social factors which are responsible for putting the individual in a stressful situation apart from his/her situation, the individual badly needs support from the society in which he/she lives in the aspect of stress reducing activity. Thus it is in this context an attempt was made by the scholar to investigate the kind of social support they are getting for managing the stress under which they undergo either at individual or at the organizational level in which they work. The information so collected is depicted in the following figure 2.

It is quite interesting to notice that the respondents do have their respective family bondage which makes it possible to get support from their family members in an attempt to reduce the stress if any affecting them (Thomas and Ganster, 1995).
From the above figure it is clear that majority of the respondents as many as $71.25 \%$ get such support and also take the help of friends as well as colleagues which are acknowledged by $38.75 \%$ and $33.75 \%$ respectively. This may be due to the fact that respondents understand the value of relations, given due regard and respect to this aspect for which it reciprocates at the time of their need.

\section{Organizational stress management technique}

In addition to attempt by an employee for stress reduction activities it is also expected that, the very organization in which he/she works come forward to the occasion and touch needful intervention for the purpose. This aspect was also probed by the scholar and the related information so collected is presented as followed in the table 2 .

From the table 2it is revealed that majority of the respondents experience the needful action initiated at their respective organizations by way of improve organizational communication to the extent of $50.0 \%$ of the respondents found it sometimes, followed by $32.5 \%$ found it always in their K.V.K. Other techniques like training, re-designing the job, rational allocation of work and employee's counseling witnessed always by $23.5 \%, 21.25 \%, 21.25 \%$ and $16.25 \%$ of the respondents respectively selected for the study. The rationality behind this situation may be attributed to the reason that free exchange of ideas, feelings and impressions through different form of organizational communication among the staff cutting across the hierarchal level facilitates emergence of ideas with more force for addressing the problem of stress.

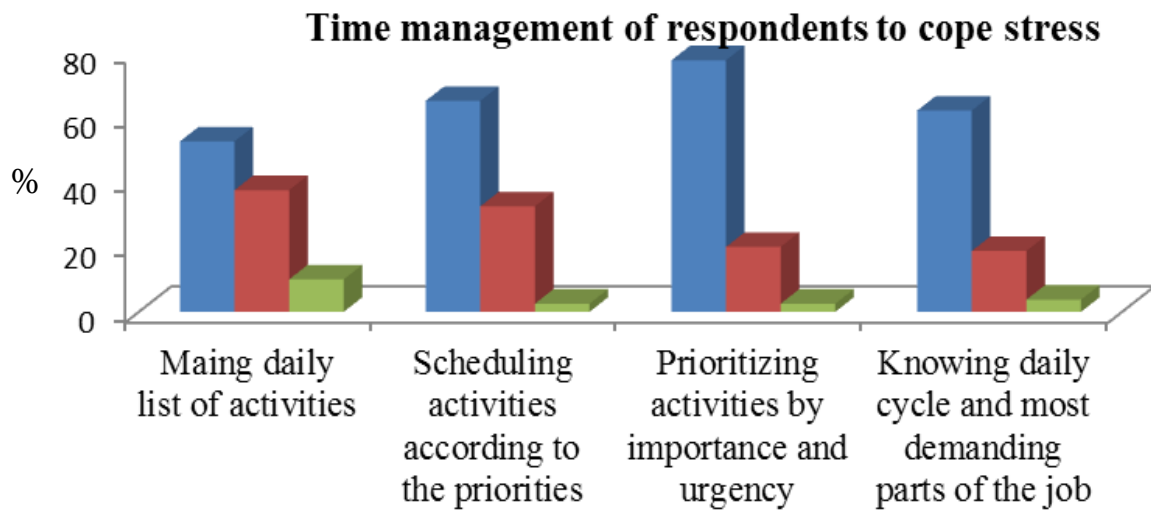

\section{Always \\ - Sometimes \\ Not at all}

Time management practices

Figure 1. Time management of respondents to cope stress 
Table 1. Physical exercise of respondents for managing stress

\begin{tabular}{l|l|cc|cccc}
\hline Sl. & \multirow{2}{*}{ No. } & Stress management technique & \multicolumn{2}{|c|}{ Always } & \multicolumn{2}{c|}{ Sometimes } & \multicolumn{2}{c}{ Not at all } \\
\cline { 3 - 7 } & & $\mathbf{( F )}$ & $\mathbf{( \% )}$ & $\mathbf{( F )}$ & $\mathbf{( \% )}$ & $\mathbf{( F )}$ & $\mathbf{( \% )}$ \\
\hline 1 & Deep breathing & 6 & 7.5 & 39 & 48.75 & 35 & 43.75 \\
2 & Mini - self massage & 5 & 6.25 & 35 & 43.75 & 40 & 50 \\
3 & Listen to music & 13 & 16.25 & 55 & 68.75 & 12 & 15 \\
4 & Say a little prayer & 36 & 45 & 29 & 36.25 & 15 & 18.75 \\
5 & Aerobics & 4 & 5 & 29 & 36.25 & 47 & 58.75 \\
6 & Brisk walking (quick walking) & 9 & 11.25 & 39 & 48.75 & 32 & 40 \\
7 & Swimming & 4 & 5 & 22 & 27.5 & 54 & 67.5 \\
8 & Bicycle riding & 4 & 5 & 32 & 40 & 44 & 55 \\
9 & Meditation & 10 & 12.5 & 41 & 51.25 & 29 & 36.25 \\
10 & Maintenance of good sleep & 28 & 35 & 36 & 45 & 16 & 20 \\
\hline
\end{tabular}

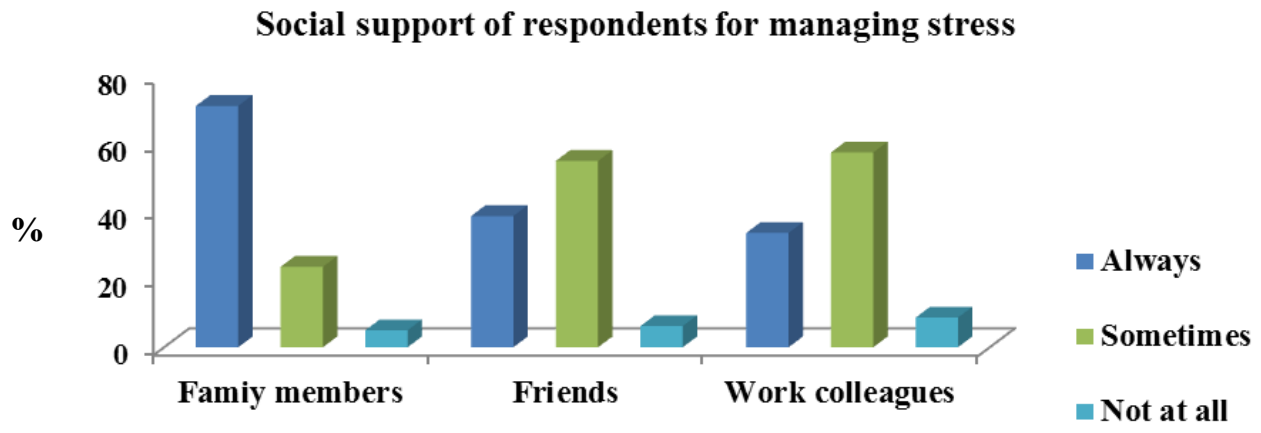

\section{Social support}

Figure 2: Social support of respondents for managing stress

Table 2. Organizational techniques taken for reducing stress of respondents

\begin{tabular}{l|l|cc|cc|cc}
\hline Sl. & \multirow{2}{*}{ No. } & \multirow{2}{*}{ Stress management technique } & \multicolumn{2}{|c|}{ Always } & \multicolumn{2}{c|}{ Sometimes } & \multicolumn{2}{c}{ Not at all } \\
\cline { 3 - 8 } & & $\mathbf{F})$ & $(\%)$ & $(\mathbf{F})$ & $(\%)$ & (F) & $(\%)$ \\
\hline 1 & Redesigning jobs & 13 & 16.25 & 32 & 40 & 35 & 43.75 \\
2 & Improved organizational communication & 26 & 32.5 & 40 & 50 & 14 & 17.5 \\
3 & Rational allocation of work place & 17 & 21.25 & 33 & 41.25 & 30 & 37.5 \\
4 & Employees counseling & 17 & 21.25 & 31 & 38.75 & 32 & 40 \\
5 & $\begin{array}{l}\text { Training and development programs help to } \\
\text { cope-up with new technology reduces stress }\end{array}$ & 13 & 16.25 & 32 & 40 & 35 & 43.75 \\
\hline
\end{tabular}

\section{CONCLUSION}

This study was conducted in Orissa state which is located in the Eastern part of India. In the study area agricultural extension functionaries experience certain level of stress, which consequently, is forcing them to be exposed to different physiological, psychological and behavioral problems. At the same time if functionaries remain exposed to stress for considerable amount of time, their job performance is compromised which directly affects the productivity of the KVK organizations. Different analytical techniques were applied to analyze the collected data. Percentage and frequency were used to identify stress management techniques. Descriptive statistics such as mean and standard deviation were employed to make further analysis of the independent variables and functionaries level of stress.

As far as the analysis on identifying the different stress management techniques being followed by the respondents is concerned, the result 
showed that time management techniques practiced by the individual functionaries were found to be in a sound position. On top of that, physical exercises: prayer and listening to music were the two techniques top practiced exercises by the majority of the respondents. Similarly, the result also showed that social support was at its best for the KVK functionaries in the process of stress management.

Stress management techniques from the organizations point of view were also studied. The outcome clearly indicated that half of the respondents experienced the needful action initiated at their respective organizations by means of improved communication.

\section{DECLARATIONS}

\section{Corresponding author}

Address: Room no. 203. Kharavela hostel, Hostel-6, Ganga nagar, Bhubaneswar, PIN-751003; Email: adityamalla32@gmail.com; Mobile no: 7978099537, 8908679095.

\section{Authors' contributions}

All authors contributed equally to this work.

\section{Competing interests}

The authors declare that they have no competing interests.

\section{\# REFERENCES}

Bano B. (2011). A study of role stress among two Indian government organizations. International Journal of Research in Commerce, IT \& Management, I (1).

Berg, A. M., Hem, E., Lau, B., \& Ekeberg, Ø. (2006). An exploration of job stress and health in the Norwegian police service: a cross sectional study. Journal of Occupational Medicine and Toxicology, London, U.K, 1(1), 26. Google Scholar, https://doi.org/10.1186/1745-6673-1-26
Bhattacharya, S., \& Basu, J. (2007). Distress, Wellness and Organizational Role Stress among IT Professionals: Role of life events and coping resources, Journal of the Indian Academy of Applied Psychology, 33(2): 169-178. Link, Google Scholar

Canadian Mental Health Association, (2005).

http://www.icar.org.in/files/KVK-TelephoneDirectory.pdf. Accessed June, 2015.

http://www.ifeet.org/stress_among_the_nursing_st udents.html. accessed May 2015

Kathirvel, N. (2009). A study on work stress and its management. The IUP Journal of Management Research, Vol. VIII(11): 28-44.

Manshor, A. T., Fontaine, R., \& Choy, C. S. (2003). Occupational stress among managers: a Malaysian survey. Journal of Managerial Psychology, 18 (6): 622 - 628. Google Scholar, https://doi.org/10.1108/02683940310494412

Olowogbon, T. S., Yoder, A. M., Fakayode, S. B., \& Falola, A. O. (2019). Agricultural stressors: identification, causes and perceived effects among Nigerian crop farmers. Journal of Agromedicine, 24(1), 46-55. Google Scholar, https://doi.org/10.1080/1059924X.2018.1538915,

Shukla, H., \& Garg, R. (2013). A study on stress management among the employees of nationalized banks. Shri Vaishnav Institute of Technology and Science, Indore, India, Voice of Research, 2(3), 72-75. Google Scholar

Sparks, K., Faragher, B., \& Cooper, C. L. (2001). Well-being and occupational health in the 21st century workplace. Journal of Occupational and Organizational Psychology, 74: 489-509. https://doi.org/10.1348/og6317901167497 Google Scholar

Thomas, L. T., \& Ganster, D. C. (1995). Impact of family-supportive work variables on workfamily conflict and strain: A control perspective. Journal of Applied Psychology, 80(1), 6. Google Scholar 